\title{
MITIGATION MEASURES OF ELECTROMAGNETIC FIELD EXPOSURE IN THE VICINITY OF HIGH FREQUENCY WELDERS
}

Wroclaw University of Science and Technology, Wrocław, Poland

Faculty of Electronics, Telecommunications and Teleinformatics Department

\begin{abstract}
Background: Presented information about the welding process and equipment, focusing on the emission of electromagnetic field (EMF) with levels significant in terms of the labor safety regulations in force in Poland - the ordinances of the Minister of Family, Labour and Social Policy that came into force on June 27, 2016 and June 29, 2016 - emerged due to harmonization with European Union directive 2013/35/EU of 26 June 2013 of the European Parliament and the Council. They presented methods of determination of the EMF distribution in the welding machine surroundings and analyzed the background knowledge from the available literature. Material and Methods: The subject of the analysis included popular high frequency welders widely used in the industry. Electromagnetic field measurements were performed in the welder operating place (in situ) during machine normal operations, using measurement methods accordant with labor safety regulations in force in Poland and according to the same guidelines, the EMF distributions and parameters having been described. Results: They presented various scenarios of particular, real examples of excessive exposure to EMF in the dielectric welder surroundings and showed solutions, ranging from simple and costless and ending on dedicated electromagnetic shielding systems, which allowed to reduce EMF exposure in some cases of more than $80 \%$ (protection zone ranges) or eliminate dangerous zone presence. Conclusions: It has shown that in the dielectric welders surrounding, significant EMF strength levels may be the result of errors or omissions which often occur during development, installation, operation or modification of welding machines. It has allowed to present the measures that may significantly reduce the exposure to EMF of workers in the welder surroundings. The role of accredited laboratories in helping in such cases was underlined. Med Pr 2017;68(6):693-703
\end{abstract}

Key words: electromagnetic field, work safety in electromagnetic fields, occupational safety and health, EMF, dielectric welders, EMC

Corresponding author: Bartłomiej Zubrzak, Wroclaw University of Science and Technology, Faculty of Electronics, Telecommunications and Teleinformatics Department, Janiszewskiego 9, 50-372 Wrocław, Poland,

e-mail: bartlomiej.zubrzak@pwr.edu.pl

Received: March 3, 2017, accepted: June 18, 2017

\section{INTRODUCTION}

High frequency welders (also known as dielectric or HF welders) are commonly used machines in almost every industry branch, usually in the process of joining plastics. Scope of applications is very broad, ranging from the manufacturing of small parts such as containers, bags, foil, plastic cladding, car equipment, through banners, awnings and ending at tent halls and stadium roofing. Basics of welding process were developed in the late 1950's and 1960's, but this technology is constantly evolving in terms of energy efficiency improvements, new ways of welding and welding technology allowing to join new types of materials [1].
Dielectric welders are often parts of automated production lines, where automatically performed welding is one of the many manufacturing stages, but they are also broadly used as independent stand-alone machines, that require the operator (or whole crew) and where some manual work is necessary, like e.g., positioning and holding of the welded material or component. In such cases the operator is very often subjected to exposure to electromagnetic fields (EMF) related with the protection zones defined in the ordinances of the Minister of Family, Labour and Social Policy enforced on June 27, 2016 and June 29, 2016 [2,3], which in some cases may require certain protective actions to reduce the exposure to EMF, which are described in more detail in the ordinance [2] which has pointed out the

Funding: project No. POIR.01.01.01-00-0012/15-00 entitled "Development of new generation innovative machines for joining plastics: PVC, silicone, teflon and ethylene, using electromagnetic energy." Project manager: Rafał Jabłoński. 
need for its documentation, taking into account "particular data on organizational and technical measures that have been applied or are intended to be applied for the purpose of eliminating or limiting individual electromagnetic hazards and the workplaces they concern." Solutions shown in this work may be assumed as such measures.

Significant EMF strength levels in the dielectric welders surrounding may have various reasons, for example, errors at the stage of machine development and design, incorrect installation of the machine in the place of the operation (e.g., inappropriate grounding), improper usage (repairs carried out by unqualified personnel), leaks resulting from damage of the device housing or shielding, or due to the particularities of machine operation (the welding/passive electrode setup, radio frequency (RF) energy transfer between the generator and the electrode or the infrastructure in the vicinity of welding).

The measurements of the electromagnetic field are usually the only method that allows to determine the EMF distribution in situ and are performed after installing and running the unit in its workplace. Computer simulation or numeric methods are used rather for the analysis purposes and exclude environment influence. The specificity of the electromagnetic field measurements methodology and exposure assessment for the purpose of occupational safety has been often discussed, e.g., by Aniołczyk et al. [4] and Kubacki et al. [5], particularly in the context of HF welders: by Aniołczyk et al. [6], Bieńkowski and Zubrzak [7], and Bieńkowski et al. [8]. The study of the electromagnetic field distribution is shown by Eriksson and Mild [9] and Conover et al. [10], while the issue related to assessment of exposure to EMF from dielectric welders is presented by Conover et al. [11].

The subjects of the analysis and measurements presented in this work are popular HF welders for plastic material welding. Some of them are automated machines that require only configuration and maintenance, and some of them are stand-alone manually operated welders. Regardless of the type, in a large simplification, welders consist of a power supply, high frequency generator (most often working at a frequency of $27.12 \mathrm{MHz}$ with power up to $20 \mathrm{~kW}$ ) and a welding tool (electrode). The energy from the mains is converted into high frequency energy in HF generator and transferred to the electrode. High frequency electromagnetic field causes vibrations of particles in the welded layers of material placed between the electrodes and heat emission from the interparticle friction. When the material's temperature reaches a predetermined value, followed by the softening and applied pressure, the permeation of molecules between the layers occurs, and thus a permanent connection is established. A side effect of the welding process is the emission of electromagnetic field, with intensity and distribution dependent on many factors, such as: construction of a welder, welding parameters, the type of welded material, electrode structure and also from the elements (especially metals) in the machine surroundings.

Studies [6-9] have shown that electromagnetic field from all protection zone ranges could be present in the vicinity of HF welders and the personnel not only related with the welder service and operation, but just passing by or having a workplace located near the welding machine could be subjected to EMF exposure with EMF levels significant from the point of view of labor safety [3]. Conclusions presented by Aniołczyk et al. [6] are clearly pointing that dielectric welder operators are "chronically exposed to high values of EMF."

The paper presents the measurement results and distribution of electromagnetic field from the welding machines at different sites (mostly production plants) where operators were subjected to excessive EMF exposure and indicated field strength was significant from the point of labor safety regulations. It aims to present simple ways of EMF exposure reduction from HF welder surroundings, supported by real examples and scenarios observed during cooperation with the industrial sector and machine manufacturers, for which worker health and safety is a priority.

\section{MATERIAL AND METHODS}

Presented situations and welders are selected particular cases which emerged during the electromagnetic field measurements in varied HF welder surroundings, mostly ordered by owners or manufacturers. Encountered phenomena were commonly a cause of significant deterioration of operator working conditions or in worst cases - precluded the unit exploitation. They showed 6 particular welders from various sites, all of them were installed inside plants and required the operating personnel. We can group them into 4 different types of scenarios:

1. The secondary source of electromagnetic field.

2. Improper usage.

3. Construction errors at the development stage.

4. Machines that require electromagnetic shielding. 
Measurements were taken before and after corrective actions suggested by authors had been taken, mostly small technical changes or modifications of the machine placement relative to the plant infrastructure/ construction or minor reorganization of work, but also using specialized shielding systems. In each of presented scenarios, the welder was placed in the production plant premises at the distance of at least $100 \mathrm{~cm}$ away from the metal structural elements, walls and equipment. The measurements were carried out using broadband electromagnetic field meter Narda NBM-550 No. B-0653 with EMF probe type EF0392 No. A-0079 with certified calibration No. LWiMP/W/034/2015 issued by an accredited calibration laboratory AP-078 and made in accordance with both requirements of the norm PN-T-06580-3:2002 [12] and the regulation currently in force in Poland [2,3] (emerged recently due to harmonization with the Directive 2013/35/EU [13]) with the expanded uncertainty of $15 \%$.

The ranges of protection zones and a maximum field strength measured in the axis of the welder operator body were the criteria for the analysis. Protection zone border values depend on the frequency and the component of measured EMF and for the targeted welders, operated at $27 \mathrm{MHz}$ frequency and electric component, those values are: $7 \mathrm{~V} / \mathrm{m}$ for the intermediate zone, $20 \mathrm{~V} / \mathrm{m}$ for the hazardous zone and $240 \mathrm{~V} / \mathrm{m}$ for the dangerous zone. During measurements both EMF components were measured, but it showed, that the electric component was dominant, so for the purpose of clarity of images, the magnetic component was omitted.

\section{RESULTS}

The study showed that in the surrounding of the dielectric welder, significant EMF strength levels may occur even fields from the dangerous zone (above $240 \mathrm{~V} / \mathrm{m}$ ). Electromagnetic field level and distribution depend on many factors and the reduction of exposure may be achieved in various ways, starting from the simplest and cheapest solutions, such as changes in the unit placement, and ending with special shielding systems, accordingly to scenarios presented below.

\section{The secondary source of electromagnetic field}

Excessive exposure of workers to EMF is usually linked with the EMF source, but there are situations, where not the generating device, but the incorrect location or improper selection of objects placed in the welder surroundings is the cause of the problem. It may lead to a phenomenon where the metal object near the EMF source starts to act as a secondary source, as a passive component affecting, sometimes dramatically, the field distribution (causing its concentration or dispersion).

The Figure 1 shows the example where the HF welder was installed directly under the main air supply duct for the air conditioning system which was hidden from sight behind the suspended ceiling. The measurement results indicating much greater levels and abnormal protection zone ranges provoked the authors to seek the source of this anomaly and that's how the unfortunate unit placement was discovered. Moving the welder $150 \mathrm{~cm}$ perpendicularly to the main duct axis

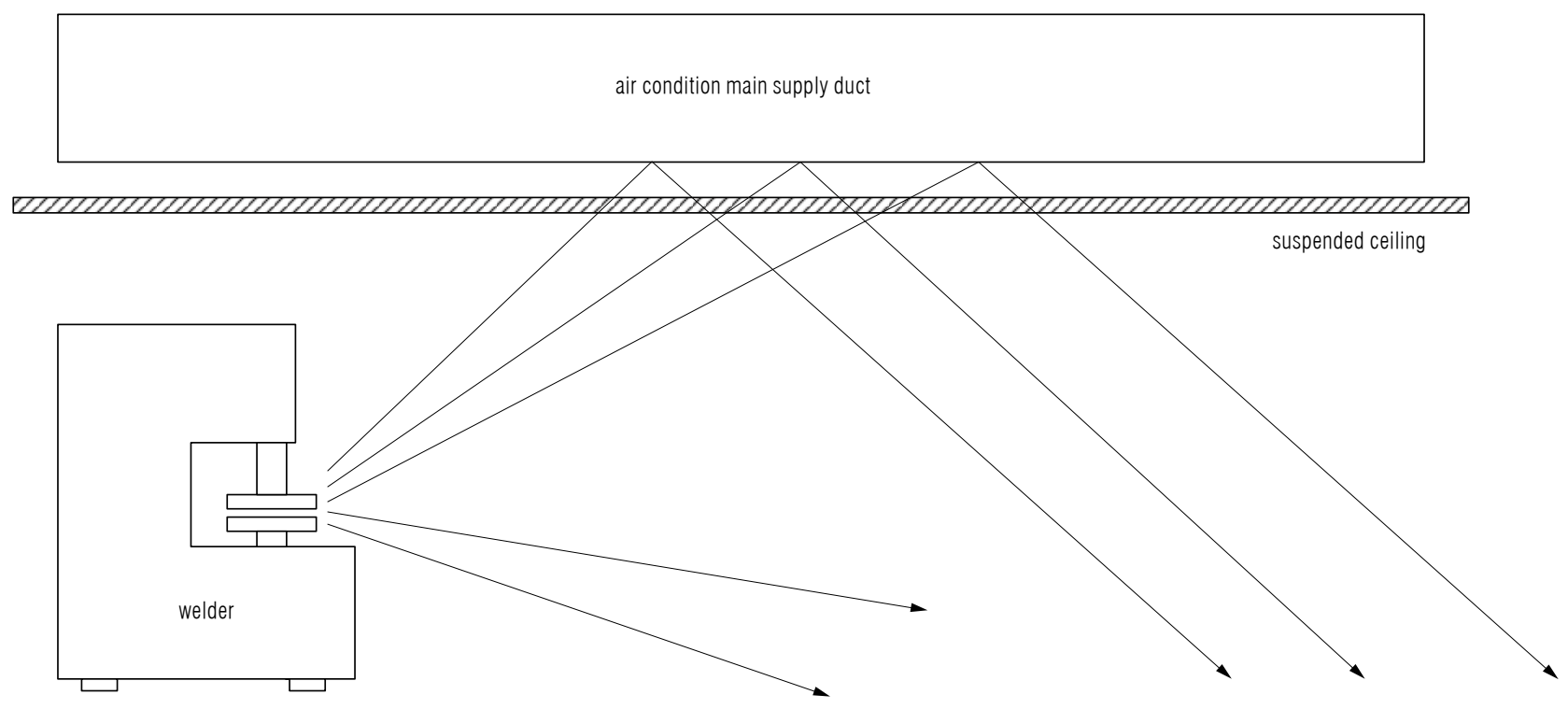

Fig. 1. High frequency welder placed under the air condition main supply duct (the secondary source of electromagnetic field (EMF)) 


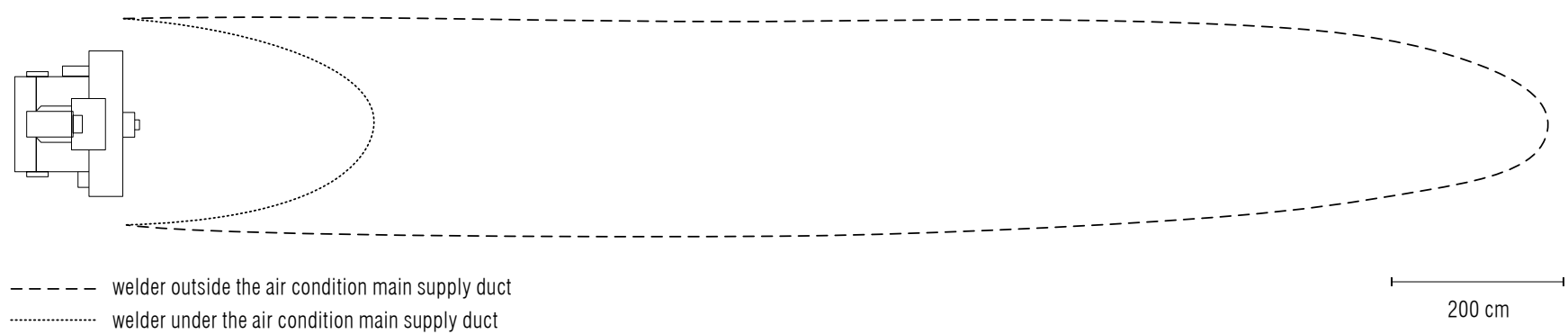

Fig. 2. Intermediate protection zone ranges before and after the high frequency welder placement change

resulted in almost 5-fold reduction in the range of the intermediate zone (Figure 2) and thus eliminated the exposure to EMF of personnel in other workplaces not directly involved in the welding process. The results of measurements before and after changing the welder placement were shown in the Table 1 . The Photo 1 presents the welding machine with an operator and air conditioning installation above the suspended ceiling.

Another example of a secondary source of electromagnetic field, this time directly at the welder operator's workplace, was a lamp with a metal arm and metal bulb housing, used for lightning the workspace (Photo 2). Those elements, which had not been an original part of a welder, but just an unconsidered improvement, had become secondary sources which affected EMF distribution to the extent that the operator's seat was in the hazardous zone range (Figure $3 a$ ). Just by modifying the placement of the lamp and the arm setting, a significant reduction of protection zone ranges was achieved (Figure $3 \mathrm{~b}$ ), so that the replacement of the lamp for a model with a plastic housing was suggested. The EMF measurement results before and after the lamp modification are summarized in the Table 2. This simple procedure reduced the exposure to EMF decreasing the hazardous zone range by $60 \%$, and most importantly - this zone ceased to cover the operator's seat.

Looking at the Photo 2, another secondary source may be noticed, which is the tabletop of the welder. In a)

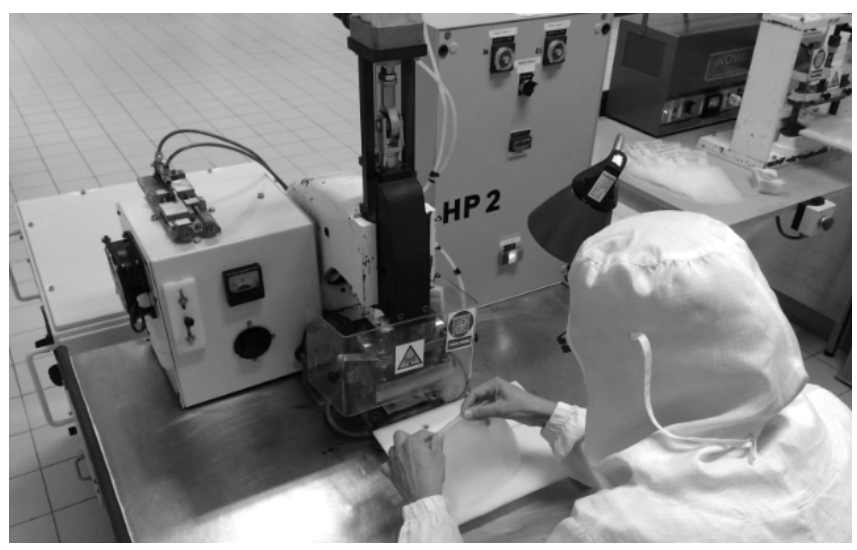

b)

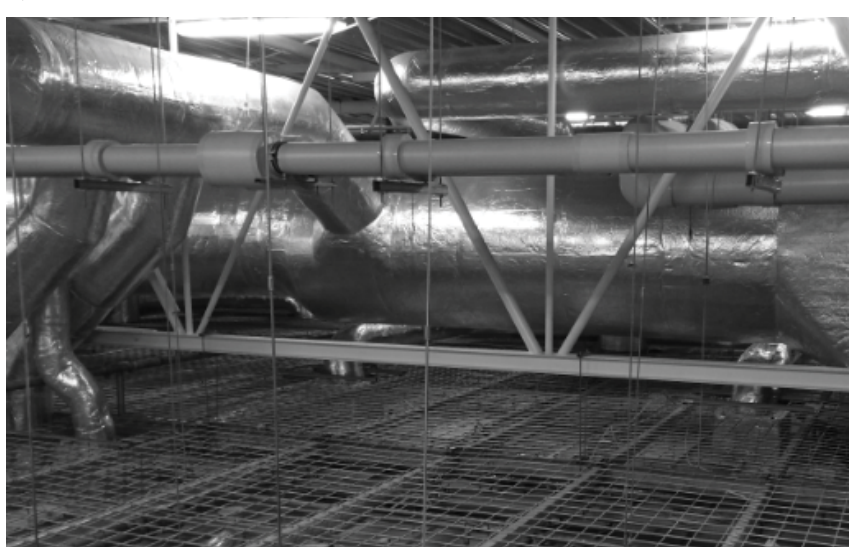

Photo 1. a) High frequency welder, b) air condition main supply duct (the secondary source of electromagnetic field) placed above the suspended ceiling

Table 1. Electromagnetic field (EMF) exposure and protection zone ranges before and after the high frequency welder placement change

\begin{tabular}{ccccccc}
\hline \multirow{2}{*}{$\begin{array}{c}\text { Welder } \\
\text { placement }\end{array}$} & \multicolumn{2}{c}{ Operator WP 1 } & \multicolumn{2}{c}{ Intermediate zone } & Hazardous zone \\
\cline { 2 - 6 } & $\begin{array}{c}\text { EMF } \\
{[\mathrm{V} / \mathrm{m}]}\end{array}$ & $\begin{array}{c}\text { EMF reduction } \\
{[\%]}\end{array}$ & $\begin{array}{c}\text { range } \\
{[\mathrm{cm}]}\end{array}$ & $\begin{array}{c}\text { range reduction } \\
{[\%]}\end{array}$ & $\begin{array}{c}\text { range } \\
{[\mathrm{cm}]}\end{array}$ & $\begin{array}{c}\text { range reduction } \\
{[\%]}\end{array}$ \\
\hline Under the main duct $^{1}$ & 57 & - & 1500 & - & 300 & - \\
Outside the main duct & & 30 & 47 & 320 & 80 & 180 \\
\hline
\end{tabular}

${ }^{1}$ Air condition main supply duct - the secondary source of EMF. WP - workplace. 
the case on the left side, it is made of a chipboard, and on the right side - from a metal plate, which is an excellent reflector for the electromagnetic field, on the one hand, reducing EMF under the table (operator legs), but at the same time resulting in increased exposure of the operator's head.

\section{Improper usage}

Improper usage may also be the cause of excessive exposure to EMF in welding surroundings. Welder owners often entrust the maintenance and repair in their own technical staff who do not always have sufficient knowledge and competence to carry out maintenance work or

Table 2. Electromagnetic field (EMF) exposure and protection zone ranges before and after desktop lamp placement change at the high frequency welder operator's workplace

\begin{tabular}{lcccccc}
\hline & \multicolumn{2}{c}{ Operator WP 1 } & \multicolumn{2}{c}{ Intermediate zone } & \multicolumn{2}{c}{ Hazardous zone } \\
\cline { 2 - 6 } Lamp placement & $\begin{array}{c}\text { EMF } \\
{[\mathrm{V} / \mathrm{m}]}\end{array}$ & $\begin{array}{c}\text { EMF reduction } \\
{[\%]}\end{array}$ & $\begin{array}{c}\text { range } \\
{[\mathrm{cm}]}\end{array}$ & $\begin{array}{c}\text { range reduction } \\
{[\%]}\end{array}$ & $\begin{array}{c}\text { range } \\
{[\mathrm{cm}]}\end{array}$ & $\begin{array}{c}\text { range reduction } \\
{[\%]}\end{array}$ \\
\hline Default & 27 & - & 80 & - & 140 & - \\
Changed & 17 & 37 & 30 & 62 & 90 & 36 \\
\hline
\end{tabular}

WP - workplace.

a)

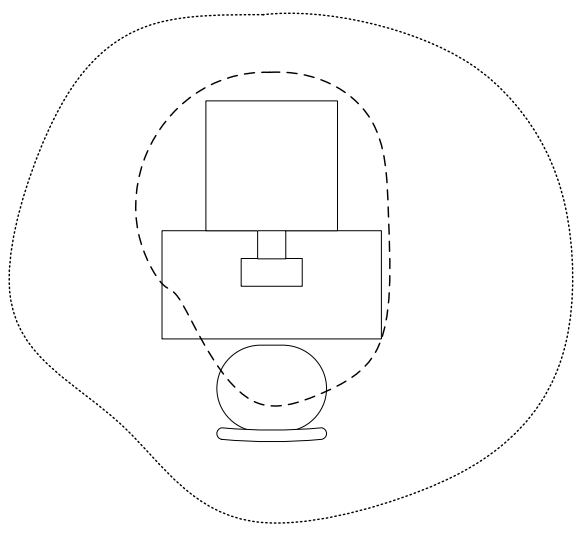

b)

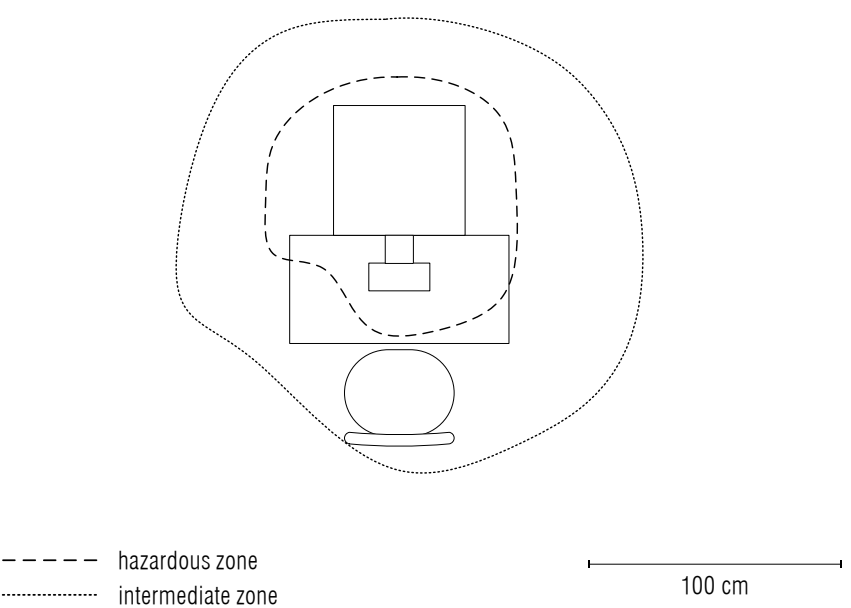

Fig. 3. Electromagnetic field (EMF) exposure reduction of high frequency welder operator by modifying desktop lamp placement at the workstation: a) default lamp placement,

b) changed lamp placement a)

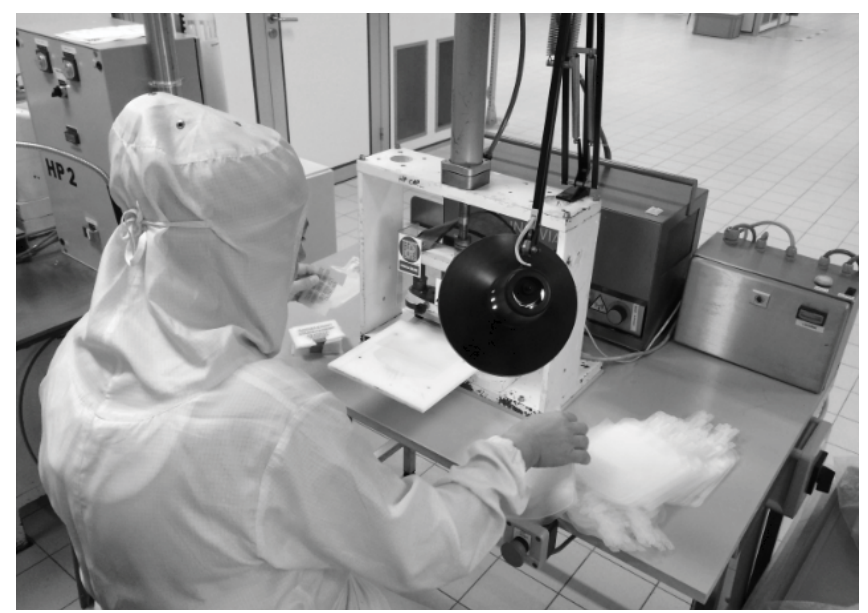

b)

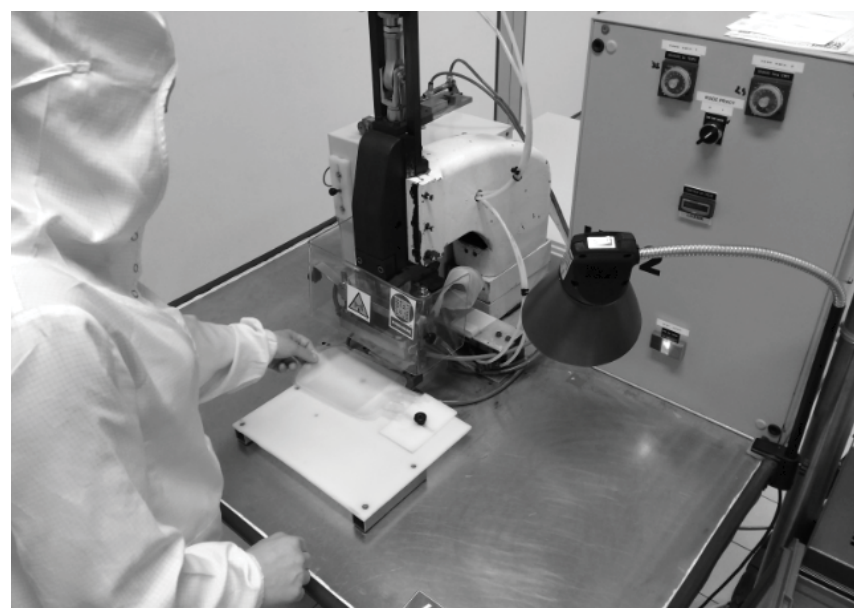

Photo 2. Desktop lamp (secondary electromagnetic field (EMF) source) at the high frequency welder operator's workplace, and different tabletops - a) wooden, b) covered with metal plate (secondary EMF source) 
modification of such specific machines. In addition, it is recommended that after each repair and reconfiguration, control measurements of the electromagnetic field should be performed in order to determine, whether the EMF distributions have been changed or not. For that reason an appropriate measuring equipment is required, in which sometimes, even a professional service team isn't equipped and trained for. The Figure 4 shows the difference in EMF distribution around the unit in which the faulty ground connection was made. From the machine operator's point of view, everything seemed to be right because it did not affect the welding process or weld quality itself. The Figure 4 illustrates how drastically the ranges of protection zones near the welder change.

The Table 3 presents the measurement results with normal and faulty grounding connection. You can notice that the reduction in the protection zone ranges reaches almost $50 \%$. In this particular case the operator body axis measurement does not change much (3\% reduction).

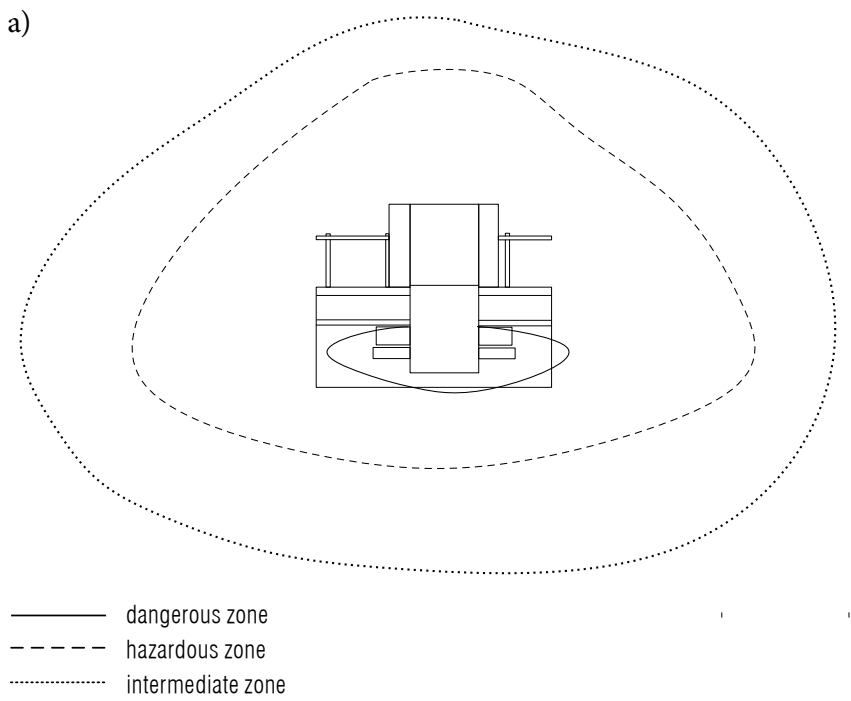

\section{Construction errors on the development stage}

Development of a high frequency welder is a very complex process. High power and high frequency circuits require different approaches, both mechanical and electrical, from ordinary high power machines. Phenomena related with high frequency power transfer, vacuum tube generator specifics and strong electromagnetic fields must be taken into account when designing welder elements, such as: power supply, control circuits, HF power transfer system, chassis, safety systems, etc. Sometimes even the least apparent elements may be critical or causing problems, such as energy or EMF leakages. Usually it has a reflection in the welder performance or the quality of the weld, but in some cases it may go unnoticed. In the presented example below 2 problems emerged during the development.

The first problem was related to access door for the air filter which despite quite a good shielding still caused electromagnetic field leakage from the machine housing. The second issue was the improperly installed control cable that, despite the lack of direct connections

b)

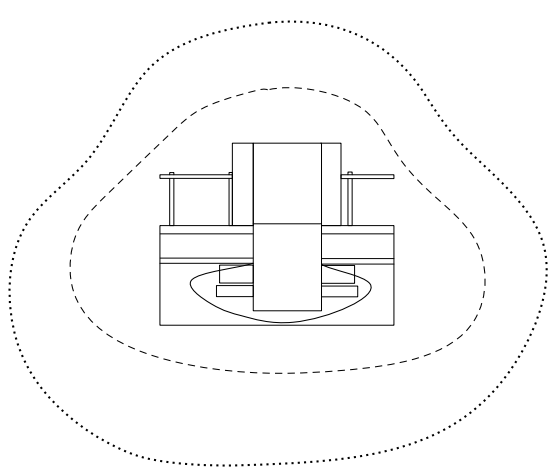

$200 \mathrm{~cm}$

Fig. 4. Electromagnetic field (EMF) protection zone ranges reduction by grounding change: a) high frequency welder with faulty grounding, b) high frequency welder with correctly connected grounding

Table 3. Electromagnetic field (EMF) exposure and protection zone ranges for properly and faulty connected grounding of high frequency welder

\begin{tabular}{lcccccccc}
\hline & \multicolumn{2}{c}{ Operator WP 1 } & \multicolumn{2}{c}{ Intermediate zone } & \multicolumn{2}{c}{ Hazardous zone } & Dangerous zone \\
\cline { 2 - 8 } $\begin{array}{l}\text { Grounding } \\
\text { connection }\end{array}$ & $\begin{array}{c}\text { EMF } \\
{[\mathrm{V} / \mathrm{m}]}\end{array}$ & $\begin{array}{c}\text { EMF } \\
\text { reduction } \\
{[\%]}\end{array}$ & $\begin{array}{c}\text { range } \\
{[\mathrm{cm}]}\end{array}$ & $\begin{array}{c}\text { range } \\
\text { reduction } \\
{[\%]}\end{array}$ & $\begin{array}{c}\text { range } \\
{[\mathrm{cm}]}\end{array}$ & $\begin{array}{c}\text { range } \\
\text { reduction } \\
{[\%]}\end{array}$ & $\begin{array}{c}\text { range } \\
{[\mathrm{cm}]}\end{array}$ & $\begin{array}{c}\text { range } \\
\text { reduction } \\
{[\%]}\end{array}$ \\
\hline Faulty & 87 & - & 420 & - & 260 & - & 50 & - \\
Properly & 84 & 3 & 240 & 43 & 120 & 54 & 40 & 20 \\
\hline
\end{tabular}

WP - workplace. 
with HF welding systems but still made of conducting material, worked as a secondary source of electromagnetic field. Still, it didn't affect its functionality but caused unnecessary EMF emission.

The solution for the first problem was an additional shielding net, and for the second problem - application of ferrite filters on both ends of the control cable. The Photo 3 presents the problematic control cable (black vertical cable), access door to air filter and applied additional net shielding. The Figure 5 shows the EMF distribution before applying of the suggested solutions. After modifications, there were no significant EMF levels in the HF welder surroundings and no presence of protection zone, which was shown in the Table 4.

\section{Machines that require electromagnetic shielding}

Sometimes the measures, like the one presented previously, are not suitable or not enough sufficient, either the cause is related with the welder HF circuits itself. The only solution that remains is the electromagnetic field shielding. In practice, the design of the shielding

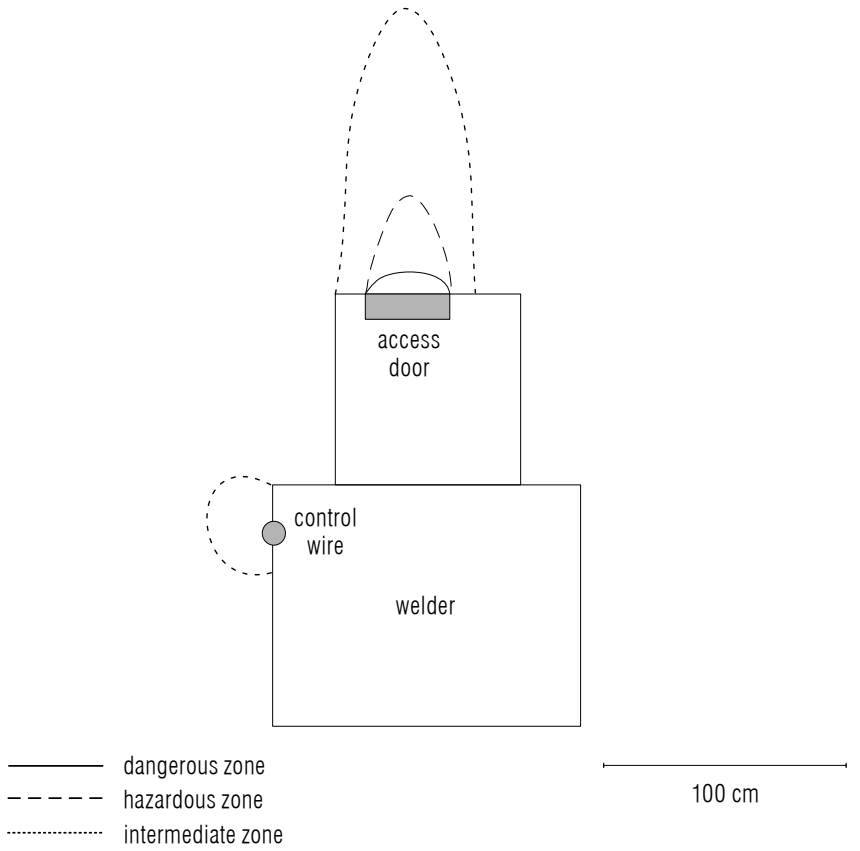

Fig. 5. Electromagnetic field (EMF) protection zone ranges before fixing control wire and access door for the air filter of high frequency welder a)

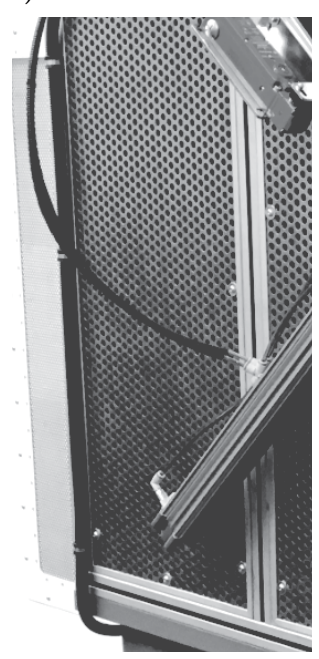

b)

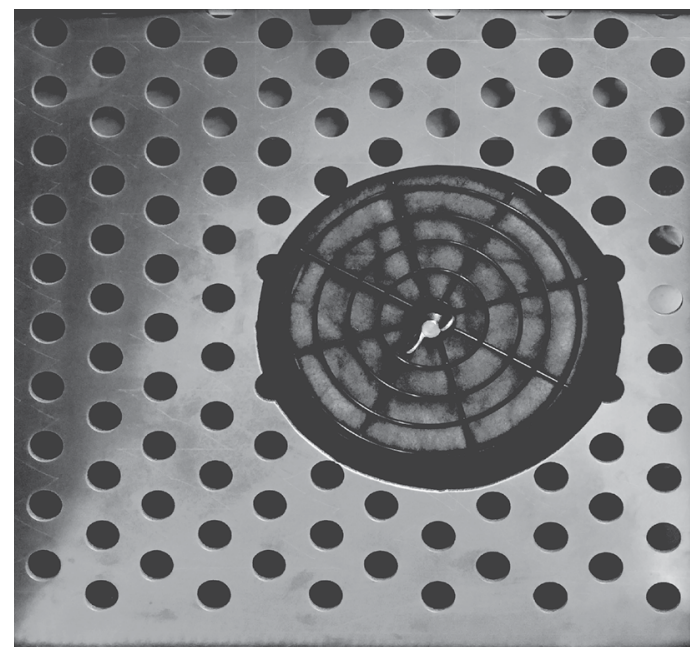

c)

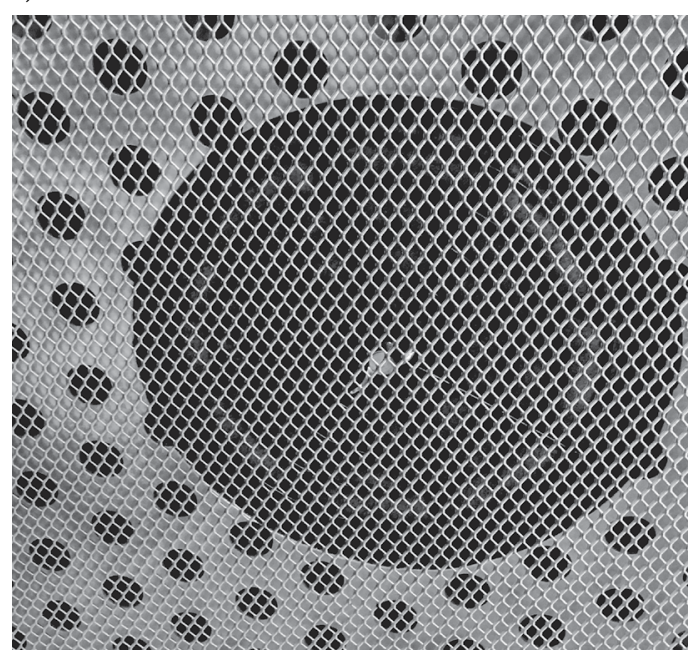

Photo 3. Problematic high frequency welder elements as the effects of malpractice at the development stage:

a) not shielded signal cable, b) dust filter access door before additional shielding, c) dust filter access door after additional shielding

Table 4. Electromagnetic field (EMF) protection zone ranges before and after fixing control wire and access door for the air filter of high frequency welder

\begin{tabular}{|c|c|c|c|c|c|c|}
\hline \multirow{2}{*}{$\begin{array}{c}\text { Measurement } \\
\text { point }\end{array}$} & \multicolumn{4}{|c|}{$\begin{array}{l}\text { Zone range } \\
{[\mathrm{cm}]}\end{array}$} & \multirow{2}{*}{\multicolumn{2}{|c|}{$\begin{array}{c}\text { Reduction } \\
{[\%]}\end{array}$}} \\
\hline & \multicolumn{2}{|c|}{ before shielding } & \multicolumn{2}{|c|}{ after shielding } & & \\
\hline Intermediate zone & 40 & 120 & 10 & 10 & 75 & 92 \\
\hline Hazardous zone & - & 50 & - & 0 & - & 100 \\
\hline
\end{tabular}


is not a simple task and should be outsourced to qualified research centers. Lack of proper knowledge and selfconstruct installations often give a counterproductive effect, resulting in increased range of protective zones because, e.g., not properly designed shielding becomes a secondary source of EMF or is not properly placed and connected. There is also the possibility of coupling of the shielding with a generator system, which in extreme cases may even affect the parameters of the welder. Shielding is designed depending on specific construction and operation of the machine. Sometimes it requires free ac-

a)

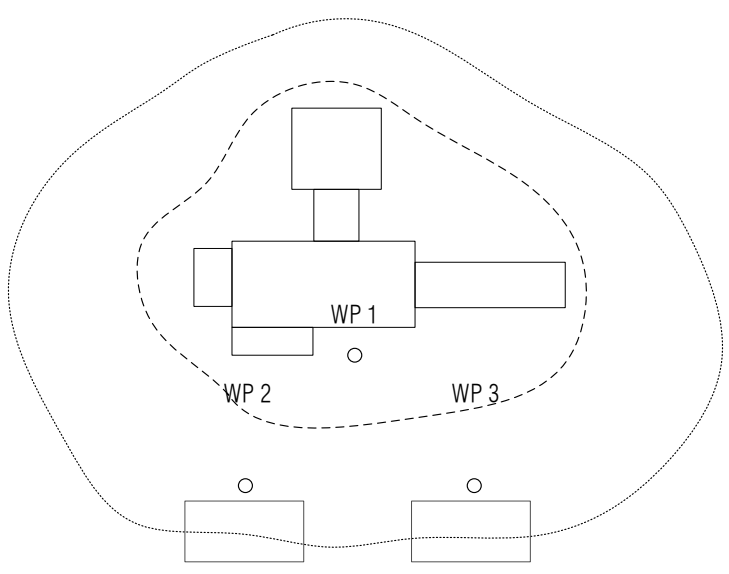

b)

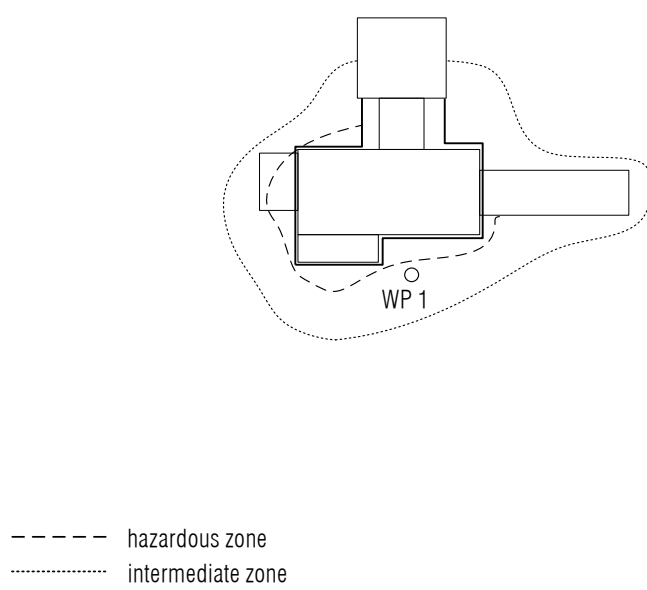

$100 \mathrm{~cm}$

WP - workplace.

Fig. 6. Electromagnetic field (EMF) protection zone ranges at high frequency welder No. 1: a) before the shielding installation, b) after the shielding installation cess to certain elements of the device or it requires to allow visual inspections (shielding net with proper mesh).

The Photo 4 shows the welding machine before and after the shielding installation, and the Figure $6-$ the change in the EMF distribution in the vicinity of the device. The intermediate zone was reduced to such an extent that other workers (workplace (WP) 2 and WP 3), not associated with the welding process, were no longer put to exposure to EMF, and the welder operator's exposure was reduced from the hazardous zone to the intermediate zone range.

a)

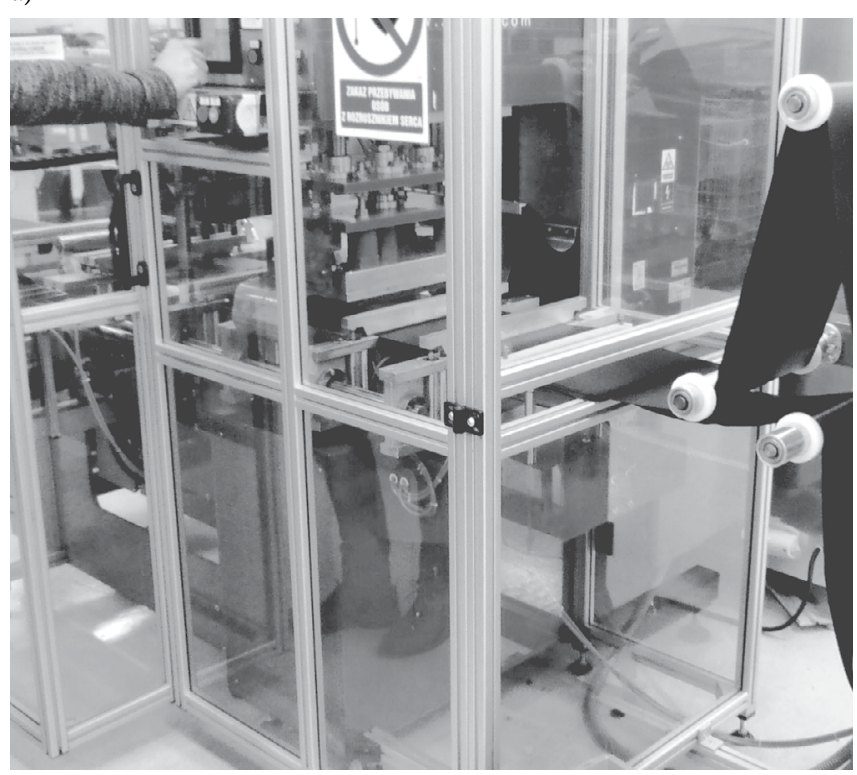

b)

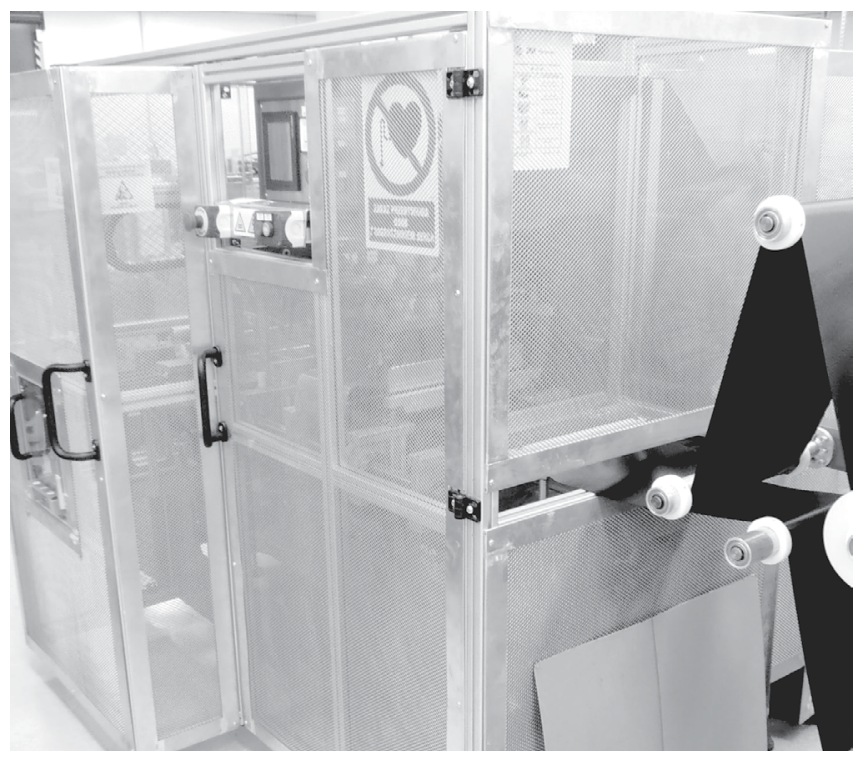

Photo 4. High frequency welder No. 1: a) before the shielding installation, b) after the shielding installation 
A similar situation took place in the case of the second presented welder. The main operator was working in the hazardous zone range and the exposure assessment (according to the ordinances [2,3]) showed, that his work time should be limited to approx. 15 min of effective welding during one shift, keeping the permissible exposure limit (exceeding this time caused excessive exposure).

To improve working conditions, a shielding system was designed and applied. The effects are shown in the Photo 5 and the Figure 7. In addition to the signifi-

a)

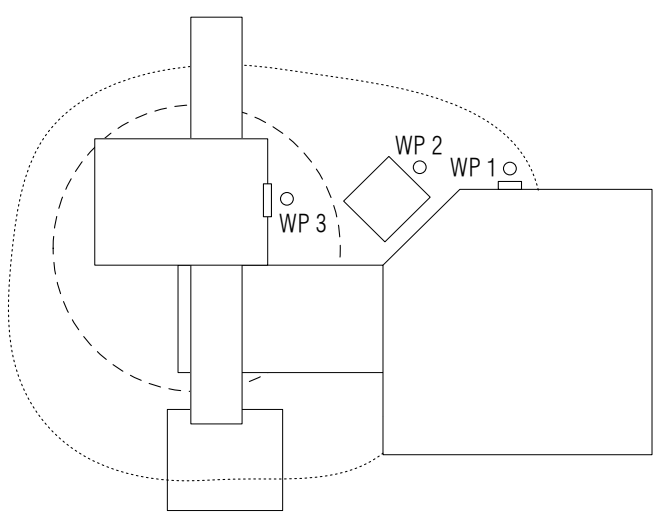

b)

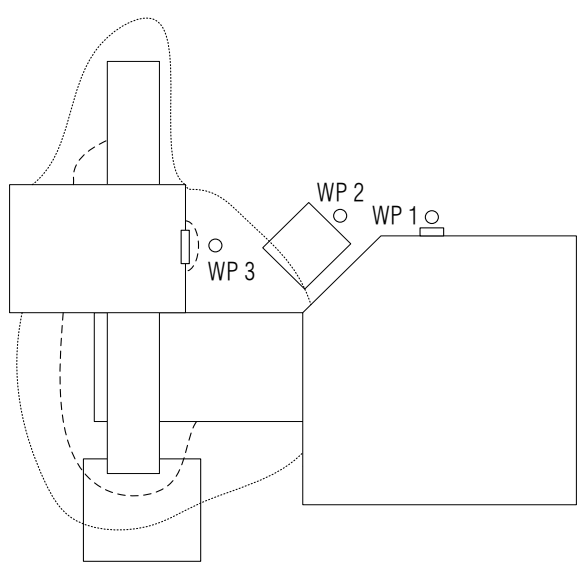

hazardous zone

intermediate zone

WP - workplace.

Fig. 7. Electromagnetic field (EMF) protection zone ranges at high frequency welder No. 2: a) before the shielding installation,

b) after the shielding installation cant EMF levels reduction in front of the control panel, the support staff preparing welding elements (WP 2 and WP 3 in Figure 7) were no longer put into EMF exposure.

The EMF measurements showing shielding results are shown in the Table 5 . In the case of welder No. 1, the ranges of the protection zones and the EMF strength measured in the body axis of the operator were reduced by approx. 70\%, while in the case of welder No. 2 - up to $50 \%$. The applied shielding didn't affect the parameters of the welding process, and significantly improved the workplace conditions.

a)

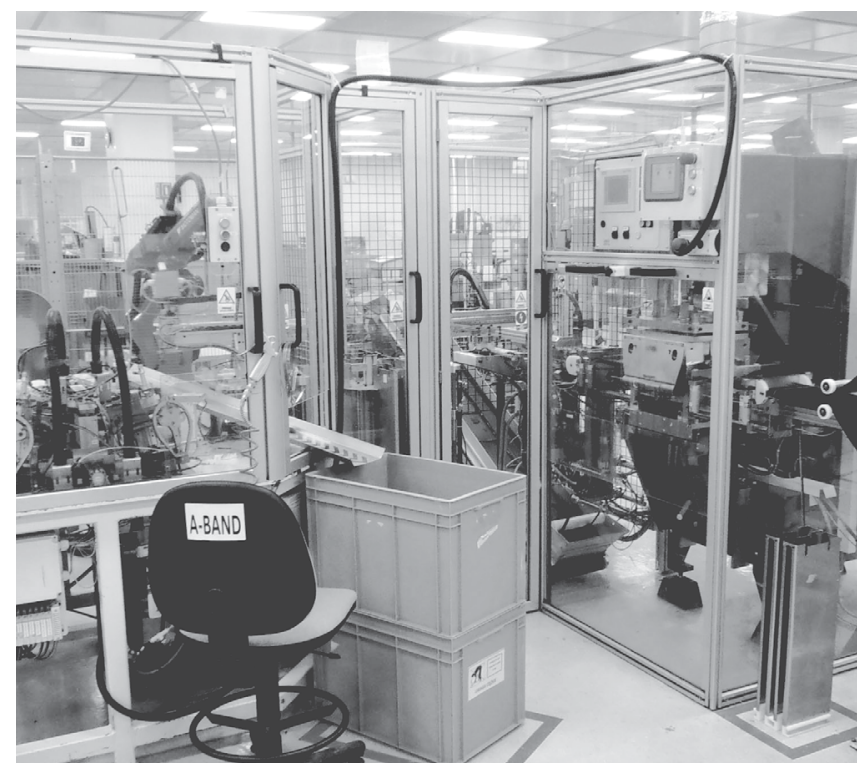

b)

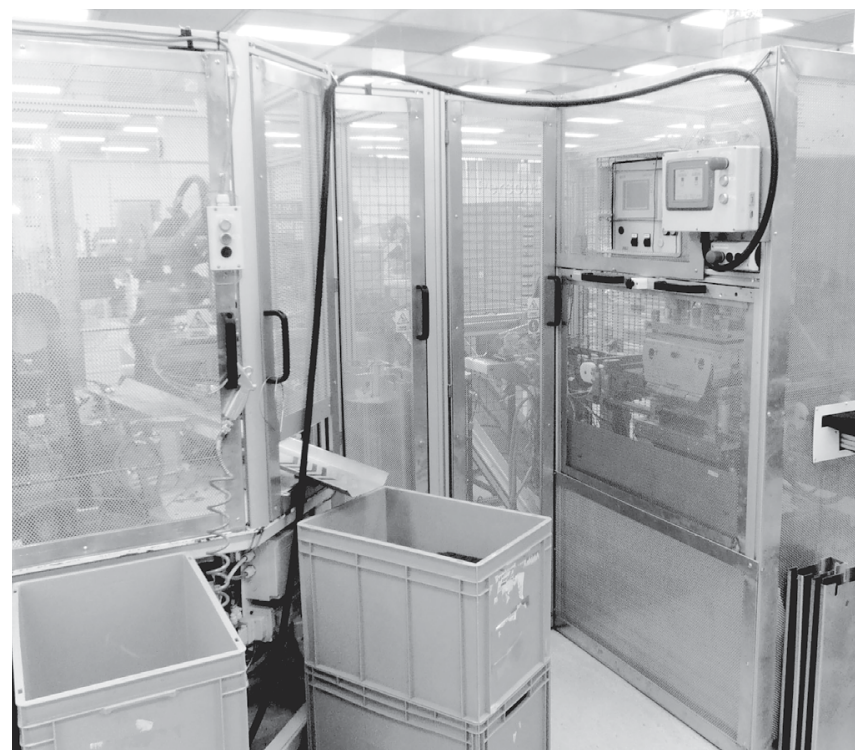

Photo 5. High frequency welder No. 2: a) before the shielding installation, b) after the shielding installation 
Table 5. Electromagnetic field (EMF) exposure and protection zone ranges before and after the shielding installation at high frequency welder

\begin{tabular}{|c|c|c|c|c|c|c|c|c|c|c|}
\hline \multirow{3}{*}{$\begin{array}{l}\text { Measurement } \\
\text { point }\end{array}$} & \multicolumn{5}{|c|}{ Welder No. 1} & \multicolumn{5}{|c|}{ Welder No. 2} \\
\hline & \multicolumn{2}{|c|}{ before shielding } & \multicolumn{2}{|c|}{ after shielding } & \multirow{2}{*}{$\begin{array}{l}\text { reduction } \\
{[\%]}\end{array}$} & \multicolumn{2}{|c|}{ before shielding } & \multicolumn{2}{|c|}{ after shielding } & \multirow{2}{*}{$\begin{array}{c}\text { reduction } \\
{[\%]}\end{array}$} \\
\hline & $\begin{array}{c}\mathrm{EMF} \\
{[\mathrm{V} / \mathrm{m}]}\end{array}$ & $\begin{array}{l}\text { zone range } \\
\quad[\mathrm{cm}]\end{array}$ & $\begin{array}{c}\mathrm{EMF} \\
{[\mathrm{V} / \mathrm{m}]}\end{array}$ & $\begin{array}{l}\text { zone range } \\
{[\mathrm{cm}]}\end{array}$ & & $\begin{array}{c}\mathrm{EMF} \\
{[\mathrm{V} / \mathrm{m}]}\end{array}$ & $\begin{array}{l}\text { zone range } \\
\quad[\mathrm{cm}]\end{array}$ & $\begin{array}{c}\text { EMF } \\
{[\mathrm{V} / \mathrm{m}]}\end{array}$ & $\begin{array}{l}\text { zone range } \\
\quad[\mathrm{cm}]\end{array}$ & \\
\hline Operator WP 1 & 60 & - & 18.5 & - & 69 & 100.0 & - & 14.0 & - & 86 \\
\hline Operator WP 2 & 18 & - & 4.1 & - & 77 & 9.2 & - & 5.1 & - & 45 \\
\hline Operator WP 3 & 13 & - & 3.7 & - & 72 & 7.1 & - & 3.3 & - & 54 \\
\hline Control panel & 90 & - & 65.0 & - & 28 & 110.0 & - & 50.0 & - & 55 \\
\hline Intermediate zone & - & 250 & - & 60 & 76 & - & 120 & - & 60 & 50 \\
\hline Hazardous zone & - & 120 & - & 30 & 75 & - & 50 & - & 30 & 40 \\
\hline
\end{tabular}

WP - workplace.

\section{DISCUSSION}

The paper presents several examples illustrating reallife examples of excessive exposure to the electromagnetic field of high frequency welder operators and measures of reducing it. The authors showed that it could be caused by the specifics of the welder operation but it also may be the result of other factors, such as: EMF secondary sources presence, human error, ignorance of issues related to the electromagnetic field and errors in the machine installation or maintenance.

Presented cases showed that using the knowledge and experience of qualified laboratories performing measurements could often reduce exposure and protection zone range without significant capital expenditure, meeting the requirements of the new regulations $[2,3]$. Taken actions often drastically reduced the exposure to EMF, contributing to the improvement of the health and safety of HF welder operators. Summary in the Table 6 shows that operator exposure to EMF may be reduced by $86 \%$ and the protection zones - by at least $20 \%$ up to complete reduction. This emphasizes the role of the technical competence of the laboratory staff, not only for routine measurement performance but also for the purpose of correct assessment and analysis skills. Of course, it is beyond the scope of accreditation but should be the added value to EMF measurements and contribute to the ultimate EMF measurements objectives - the usefulness of obtained results.

At the end, let's not forget about the role of the welder users who should be aware of the specifics of the phenomena that accompany the electromagnetic field in the RF welder surroundings, which, in combination with labor health and safety department awareness (supported by proper training) and appropriate measurement policy (periodic and control measurements), may make a significant contribution to preventing the occurrence of mentioned scenarios.

Table 6. Protection zone range reduction and electromagnetic field (EMF) intensity reduction measured in the body axis of high frequency welder operator by the applied solution

\begin{tabular}{|c|c|c|c|c|c|c|c|}
\hline \multirow{2}{*}{$\begin{array}{l}\text { Measurement } \\
\text { point }\end{array}$} & \multicolumn{7}{|c|}{$\begin{array}{c}\text { Reduction } \\
{[\%]}\end{array}$} \\
\hline & $\begin{array}{l}\text { welder } \\
\text { placement } \\
\text { change }\end{array}$ & $\begin{array}{l}\text { lamp } \\
\text { placement } \\
\text { change }\end{array}$ & $\begin{array}{c}\text { properly } \\
\text { connected } \\
\text { grounding }\end{array}$ & $\begin{array}{l}\text { control wire } \\
\text { shielding }\end{array}$ & $\begin{array}{l}\text { access door } \\
\text { shielding }\end{array}$ & $\begin{array}{c}\text { welder No. } 1 \\
\text { shielding }\end{array}$ & $\begin{array}{l}\text { welder No. } 2 \\
\text { shielding }\end{array}$ \\
\hline Operator & 47 & 37 & 3 & - & - & 69 & 86 \\
\hline Intermediate zone & 80 & 62 & 43 & 75 & 92 & 76 & 50 \\
\hline Hazardous zone & 40 & 36 & 54 & - & 100 & 75 & 40 \\
\hline Dangerous zone & - & - & 20 & - & 100 & - & - \\
\hline
\end{tabular}




\section{CONCLUSIONS}

The high frequency welder is a source of electromagnetic field with values significant from the point of view of labor health and safety regulations in force in Poland [2,3]. Widespread use of welding machines in many industrial branches makes exposure to EMF problematic subject for many employers. The authors have presented the common mistakes that may lead to a situation of avoidable excessive EMF exposure of the personnel working in the vicinity of welding machines. The effectiveness of the EMF shielding systems was also underlined. The analysis of the examples indicates that due to the nature of the construction and operation of welders, the only effective method of assessing the exposure of workers is by performing the in situ measurements. This work may also be an inspiration for labor health and safety agencies and inspectors, authorities as well as welding machines manufacturers to create a short guide about proper installation, usage and maintenance of high frequency welders.

\section{REFERENCES}

1. Grewell D, Benatar A. Welding of plastics: Fundamentals and new developments. Int Polym Proc. 2007;1(22):43-60.

2. [The ordinance of the Minister of Family, Labour and Social Policy from June 29, 2016 regarding the safety and hygiene at work related to the exposure to electromagnetic. Off J Laws 2016, No. 950]. Polish.

3. [The ordinance of the Minister of Family, Labour and Social Policy from June 27, 2016 changing maximum permissible concentration and intensity of harmful factors in the work environment. Off J Laws 2016, No. 952]. Polish.

4. Aniołczyk H, Mariańska M, Mamrot P. [Assessment of occupational exposure to radio frequency electromagnetic fields]. Med Pr. 2015;66(2):199-212, https://doi.org/10.13 075/mp.5893.00196. Polish.

5. Kubacki R, Kieliszek J, Sobiech J. [Standardization of methodologies for the measurement of electromagnetic fields and its effect on the quality of research]. Electr Rev. 2013; (12):367. Polish.
6. Aniołczyk H, Mamrot P, Mariańska M. [Analysis of methods for measurement and assessment of occupational exposure to electromagnetic fields in dielectric heating]. Med Pr. 2012;63(3):329-44. Polish.

7. Bieńkowski P, Zubrzak B. Electromagnetic field in high frequency welder surroundings. In: [Radioelectronics]. Proceedings of the 26th International Conference; 2016 Apr 19-20; Kosice, Slovakia. Kosice: Department of Electronics and Multimedia Communications; 2016. p. 32-5.

8. Bieńkowski P, Cała P, Zubrzak B. High frequency dielectric welder as an electromagnetic field source. In: [Applications of electromagnetism in modern techniques and medicine: XXVI Symposium on Environmental]; 2016 Jun 26-29; Wrocław, Poland. Wrocław: Polish Society of Applied Electromagnetics; 2016. p. 319-21.

9. Eriksson A, Mild KH. Radiofrequency electromagnetic leakage fields from plastic welding machines. Measurements and reducing measures. J Microw Power Electromagn Energ. 1985;20(2):95-107, https://doi.org/10.1080/ 16070658.1985.11720296.

10. Conover DL, Parr WH, Sensintaffer EL, Murray WE. Measurement of electric and magnetic field strengths from industrial radiofrequency $(15-40.68 \mathrm{MHz})$ sources. Silver Spring: Food and Drug Administration; 1976. p. 356-62.

11. Gryz K, Karpowicz J, Molenda M, Zradziński P. [Assessment of exposure to electromagnetic fields generated by welding, insulating - Comparative analysis of the requirements of national legislation and the Directive 2004/40/EC]. Bezpiecz Pr. 2006;(3):26-30.

12. PN-T-06580-3:2002. [Labour protection in electromagnetic fields and radiation of the frequency range from $0 \mathrm{~Hz}$ to $300 \mathrm{GHz}$ - Part 3: Methods of measurement and evaluation of the field on the work stands]. Polish.

13. Directive 2013/35/EU of the European Parliament and of the Council of 26 June 2013 on the minimum health and safety requirements regarding the exposure of workers to the risks arising from physical agents (electromagnetic fields) (20th individual Directive within the meaning of Article 16(1) of Directive 89/391/EEC) and repealing Directive 2004/40/EC. Off J Eur Union L 179/1 (Jun 29, 2016).
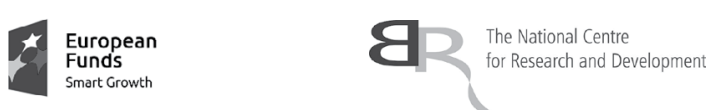

EUROPEAN UNION

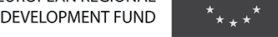

The project is co-financed by the European Union Fund under the Smart Growth Operational Programme 2014-2020, Activity 1.1 Enterprise R+D projects; Sub-measure 1.1.1. Industrial research and development work implemented by enterprises, project No. POIR.01.01.01-00-0012/15-00

This work is available in Open Access model and licensed under a Creative Commons Attribution-NonCommercial 3.0 Poland License / Ten utwór jest dostępny w modelu open access na licencji Creative Commons Uznanie autorstwa - Użycie niekomercyjne 3.0 Polska - http://creativecommons.org/ licenses/by-nc/3.0/pl/deed.en. 